Brawley. Last year and this the augmentative trials are being done on a large scale in the Imperial Valley. He is placing the parasites in commercial organic fields and comparing their control with conventional fields that use the pesticide imidacloprid.

"We are using an Eretmocerus collected from the United Arab Emirates for the augmentative studies. About 3 years of data show that you can get comparable control, and the cost is comparable in spring melons," he says.

Pickett is also using transplants as a vehicle for getting the parasites into the field. Transplants are inoculated with whiteflies, then parasites just prior to planting in the field so $95 \%$ or more of the whiteflies will be parasitized. "We think this may be a more efficient means of releasing the parasites, reducing the overall cost," he says. - Editor

\title{
Scientists see spike in Africanized bee numbers
}

A fter an unexpectedly slow spread since their 1994 arrival in the state, Africanized honey bees (AHB) may have quintupled their numbers recently in southeastern California.

UC Davis graduate student David Nielsen and UC Davis entomologist Robert Page have been charting the AHB's progress since 1995. They report that in 1997,7\% of 502 captured bees were Africanized. That figure is up almost five-fold from 1996, when $1.5 \%$ of foraging bees captured were Africanized.

"These were all foraging bees, separated from their colonies," Nielsen notes, "so each one could represent a separate colony."

The scientists sampled in a core area bounded by Palm Springs on the west, Highway 10 on the north, The Colorado River (Arizona border) on the east and the Mexican border on the south. In 1995, the researchers brought back 75 bees and none were AHB. In 1996, they brought back 196 bees and 3 were AHB; in 1997, they brought back 502 bees and 34 were AHB, Nielsen said. After capturing foraging bees in sweep nets, the scientists used UC Davis-developed DNA tests to rapidly identify AHBs, which appear identical to European honey bees.

Nielsen believes the AHB's slow initial progress could be related to several factors, one being the varroa mite, which has parasitized honey bee colonies statewide and wiped out $85 \%$ of wild bees (see page 9 ).

Varroa mites can kill off a bee colony in 6 to 18 months. The external mites lay eggs on the bee larvae. The parasites suck fluids and nutrients out of the bee during its larval and pupal stages. A bee can survive one mite, but as more parasites feed on the developing bee, the emerging adult bee may become deformed and may not be a productive member of the colony. (Another theory, not widely held, is that the mite infects the bee with a pathogen that disables the bee.) Tracheal mites, which invade bees' trachea, also contribute to the bee decline, but because they are internal they are harder to detect. Colony losses due to tracheal mites have been extensive, but it appears that colonies have varying levels of natural resistance to these mites, so they may not pose as great of an obstacle to the Africanized bees or to the beekeeping industry as varroa.

There is some evidence that Africanized bees possess some resistance to varroa mites. "We know that their populations are stable in many areas and increasing within the state," Nielsen says. "On the other hand, our feral honey bee population is down to $10 \%$ or possibly less of its original strength. It's possible that the only feral bees we see now are mainly escapees from commercial hives."

Commercial bees are surviving because beekeepers treat for varroa with fluvalinate mite strips. The future of these is clouded because there is also evidence, primarily anecdotal, that varroa mites are developing resistance to this miticide.

"I think the Africanized bee's slow advancement in the U.S. is also a function of climate," Nielsen says. "The AHB's current distribution in the U.S. includes strictly the dry, arid climates of the Southwest, but bees in these regions require urban or irrigated areas to obtain enough food and a constant supply of water to flourish. They currently have survival problems in those areas with high humidity or harsh winters."

AHB has been in Texas for a long time, but has not moved to the east - possibly because

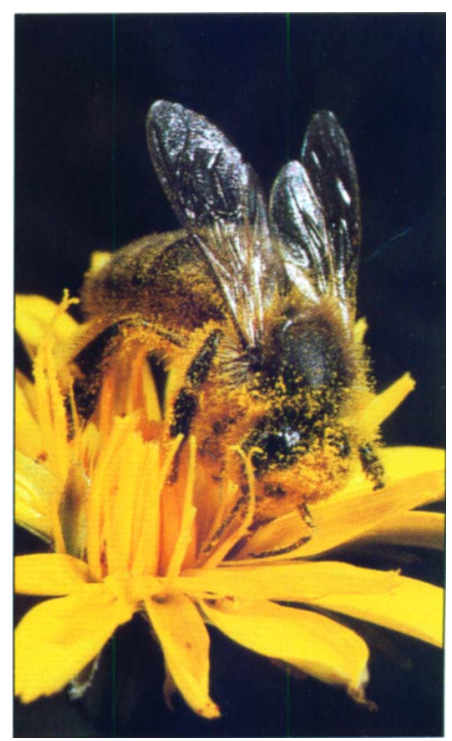

Feral honey bees, which have been nearly wiped out by the varroa mite, are one of a number of natural pollinator species on the decline. 


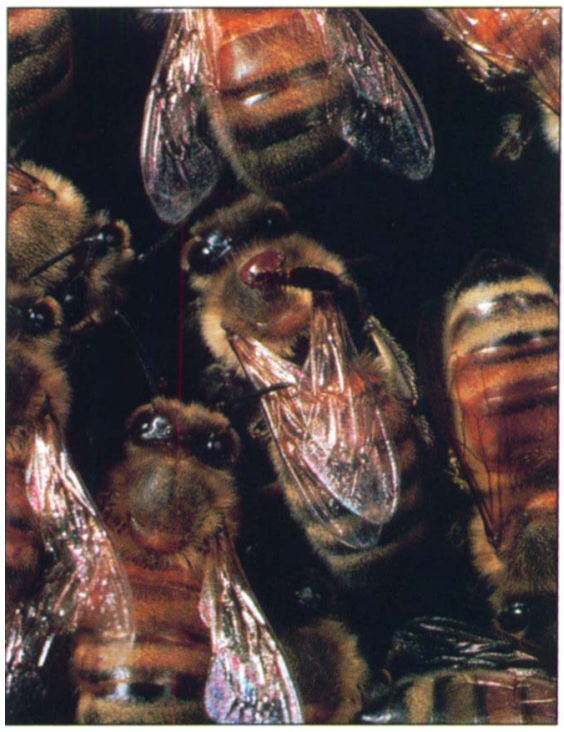

of humidity, according to Nielsen and has not moved north, possibly due to more extreme winter conditions. In Arizona, AHBs increased at phenomenal rates in Phoenix and Tucson while staying at lower numbers outside of productive urban areas. Large increases in AHB numbers were noted in 1997 along the Colorado River where food and water abound. Although lack of water during much of the year makes the area between the Colorado River and the Imperial Valley inhospitable to bees, canals and brief periods of rainfall provide enough food and water for bees to cross this region. This spring's abundant rainfall in the southeastern portion of the state has produced a carpet of flowering annuals from the Colo-

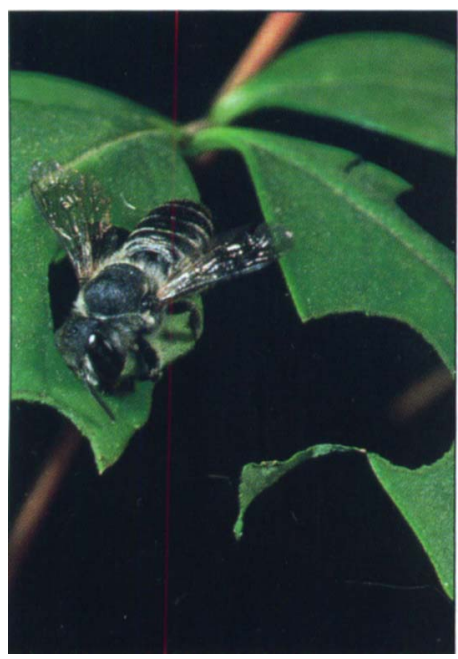

Top, a honey bee tries to dislodge a varroa mite from its thorax. Above, alfalfa leafcutter bees, which are also commercially managed for pollination, are not affected by varroa mites. rado River all the way to the coast, providing excellent opportunity for the bees to increase their range during this year.

Last year Nielsen expanded his sampling area to include sites in Anza Borrego State Park and into the mountains just east of San Diego to determine if the AHB was advancing toward the coast. However, no Africanized bees were found in the mountains and very few in the park. The finding of AHB in Palm Springs last year suggests that it may reach Los Angeles before San Diego, Nielsen says. This year the sampling area will be expanded again to determine the full extent of the bees' northern and western expansion within the state.

European and Africanized bees carry the same venom and can sting only once, but AHBs respond faster and in greater numbers. They are more likely to defend a larger area around their nest and will pursue a target $1 / 4$ mile or more. The invasion of Africanized honey bees presents not only a safety hazard, but affects the state's pollination services. Africanized colonies cannot be easily handled and moved to pollinate crop plants as European honey bees are. European honey bees are employed as pollinators for 47 different California nut, fruit, vegetable and forage seed crops valued at $\$ 1.8$ billion annually. California almonds alone require 800,000 colonies for pollination.

The declines in wild bees and the frequency of varroa mites in commercial hives is part of a larger picture of declines in pollinators, which could have not only statewide but worldwide implications for food production (see box). - Ed.

\section{Decline in pollinators could threaten food supply, biodiversity}

Numbers of wild and managed honey bee colonies in the United States have dropped by $25 \%$ since 1990 . That precipitous drop is just one part of a worldwide decline in pollinator species, according to a study published in the February issue of Conservation Biology.

Gary Nabhan of the Arizona Desert Museum in Tucson and 21 co-authors state in the introduction, "Worldwide, nearly 200 species of wild vertebrates may be on the verge of extinction, along with an untold number of invertebrate animals."

Prompted by reports of European honey bee declines in North America, pollination ecology experts evaluated the status of wild pollinators - such as butterflies, birds and bats - and found that they are also declining. The reduction in pollinators could threaten both the yield of food crops and the diversity of species around the world, the authors say.

Nabhan and his colleagues found that the $25 \%$ decline in honey bee colonies in North America could result in crop yields reduced by an estimated $\$ 5.7$ billion per year. The loss of managed and wild honey bees suggests other wild pollinators may become more important for our food supply.

While the status of wild pollinators is little known, Nabhan and his colleagues say that what we do know suggests that a scarcity of pollinators is reducing seed and fruit production in many endangered wild plants globally, including an Arizona agave, a Hawaiian silversword and a Japanese primrose.

To increase populations of pollinators, Nabhan and his colleagues call for measures such as minimizing pesticide use in agricultural fields; planting native nectarbearing wildflowers around crops, highways and golf courses; and protecting major "nectar corridors" where pollinators migrate. Besides stabilizing crop yields, an increase in wild pollinators would benefit wild plants and the many animals that eat their fruit and seeds. $-E d$. 